Archivum, LXIX, 2019, pp. 7-41

\title{
Sobre Sexismo lingüístico y visibilidad de la mujer (2012): lecturas imprecisas y tópicos infundados asociados al "Informe Bosque"
}

\author{
Manuel Cabello Pino \\ UNIVERSIDAD DE HUELVA \\ manuel.cabello@dfesp.uhu.es
}

\section{RESUMEN:}

Desde su publicación en 2012 el texto "Sexismo lingǘstico y visibilidad de la mujer", más conocido como el "Informe Bosque", se ha convertido, como es bien sabido, en uno de los más polémicos e influyentes de los últimos años. Pero, en nuestra opinión, se trata también de uno de los que ha sido objeto de las lecturas menos acertadas. En el presente artículo mostraremos cómo las reacciones mayoritariamente tan negativas que propició desde el primer momento entre los partidarios del llamado "lenguaje inclusivo" fueron fruto tanto de su propia lectura apasionada y, por eso mismo, no demasiado precisa del texto, como también de la no menos imprecisa interpretación del texto que realizaron algunos de los supuestos defensores del profesor Bosque. Dichas lecturas erróneas habrían sido motivadas por la pasión con que fue recibido y leído el documento tras más de veinte años de enfrentamiento en estado latente entre partidarios y detractores de ese tipo de lenguaje.

PALABRAS CLAVE: Sexismo lingüístico, informe Bosque, lenguaje inclusivo, masculino genérico, guías no sexistas. 
On Sexismo lingüístico y visibilidad de la mujer (2012): inaccurate readings and baseless clichés related to "Informe Bosque"

\begin{abstract}
:
Since its publication in 2012 the text "Sexismo lingüistico y visibilidad de la mujer", better known as "Informe Bosque", has turned into one of the most polemic and influential texts in the last years, as it is well known. But, in our opinion, it is one of the texts which has suffered the less accurate interpretations as well. In this article we will prove that the mostly negative reactions that this text propitiated from the very first moment among the upholders of the so called "inclusive language" were motivated so much by its own impassioned reading as by the not less inaccurate interpretations of the text made by some of the supposed defenders of Professor Bosque. These wrong interpretations would have been motivated by the passion that went with the reception and reading of the document after more than twenty years of latent confrontation between those in favor and those against this sort of language
\end{abstract}

KEY WORDS: Linguistic sexism, Bosque report, inclusive language, generic male form, non-sexist guides.

\title{
1. Introducción
}

Pocos textos académicos han generado tanta polémica en los últimos años como el informe de la RAE en colaboración con la ASALE "Sexismo lingüístico y visibilidad de la mujer", popularmente conocido como el "Informe Bosque". Su publicación en 2012 provocó un enorme revuelo tanto mediático como acadé$\mathrm{mico}^{1}$, e hizo correr ríos de tinta tanto entre los partidarios como entre los detractores del mismo. Sin embargo, una de las declaraciones más llamativas fue la de la filóloga Violeta Demonte, quien en una entrevista inmediatamente posterior a la publicación del informe lo calificaba de "extemporáneo" porque, según ella:

1Véanse Lucía Morrillo Herrero, (2014), "Repercusión mediática del informe de Ignacio Bosque «Sexismo lingüístico y visibilidad de la mujer» (2012)" en Francisco Manuel Carriscondo Esquivel (aut.) La lengua del candelero: repercusión mediática de asuntos lingüísticos: 97-134; y Carmen Llamas Saíz, (2015), "Academia y hablantes frente al sexismo lingüístico: ideologías lingüísticas en la prensa española", Circula: revie d'ideologies linguístiques, $\mathrm{n}^{\mathrm{0}}$ 1: 196-215. 
(...) no han aparecido recientemente nuevas guías o manuales que en algún momento fueron frecuentes $\mathrm{y}$, de hecho, las que se comentan en la Academia son una de 2002 y la más reciente de 2009, alguna de 2011. En todo caso, el tema no estaba en la palestra ni había ninguna demanda social; y por ello es extraño que de pronto haya aparecido ese informe. Pienso que la Academia, si tenía una opinión, podría haber hecho sugerencias oportunamente ante informes específicos y no lo ha hecho. (Soca, 2012)

Lo cierto es que todas y cada una de estas afirmaciones son, como mínimo, cuestionables. En primer lugar, las guías de lenguaje no sexista ni mucho menos habían dejado de ser frecuentes en 2012, ni eran cosa del pasado². De hecho, aunque el "Informe Bosque" se limitase a analizar solo nueve de ellas, lo cierto es que sí que habían aparecido en fecha muy reciente numerosas guías de lenguaje no sexista (al menos siete tan solo el año anterior ${ }^{3}$ ), tal como afirmaba Ignacio Bosque en las dos primeras líneas del texto, y seguirían apareciendo en los años siguientes ${ }^{4}$.

2 Susana Guerrero Salazar (2007) cataloga un total de 68 guías de lenguaje no sexista correspondientes al periodo 1986-2006.

3 Heura Marçal, Fiona Kelso y Mercè Nogués (2011): Guía para un uso no sexista del lenguaje en la Universitat Autónoma de Barcelona; Gemma Escrig Gil y Anna Sales Boix (2011): Guía de tratamiento no sexista de la información y la comunicación en la Universitat Jaume I; Carmen Marimón Llorca e Isabel Santamaría Pérez (2011): Guía para un discurso igualitario en la Universidad de Alicante; Universidad de Murcia (2011): Guía de uso no sexista del vocabulario español; Universidad de Cantabria (2011): Guía UC de Comunicación en igualdad; Antonio Briz Gómez (Coord.) (2011): Guía de comunicación no sexista; M. J. Pérez Cervera (2011): Manual para el uso no sexista del lenguaje.

4 Véanse a modo de ejemplo Susana Guerrero Salazar (2012): Guía para un uso igualitario y no sexista del lenguaje y de la imagen en la universidad de Jaén; UNED (2012): Guía de lenguaje no sexista; Universidad de Salamanca (2012): Guía de igualdad. 1) Líneas básicas del plan de igualdad entre mujeres y hombres de la Universidad de Salamanca, 2) y de la utilización de un lenguaje inclusivo; (2013): Manual del lenguaje integrador no sexista. Ministerio de la Mujer y Poblaciones Vulnerables del Perú [MIMP] (2013): Si no me nombras, no existo. Guía para el uso del lenguaje inclusivo; Mercedes Bengoechea (2016): Sugerencias para evitar el sexismo en el lenguaje administrativo; Susana Guerrero Salazar (2019): Guía para un uso igualitario del lenguaje y de la imagen en la Diputación de Huelva. 
En segundo lugar, aunque es cierto que realmente no había una gran demanda social de guías y manuales de lenguaje inclusivo, lo que sí que había habido en los años inmediatamente anteriores era una gran presión a la Academia (De Querol, 2012) por parte de determinados sectores ideológicos que contaban con una gran presencia en prensa escrita, y habían conseguido generar ya un cierto debate periodístico ${ }^{5}$. Además, esos mismos sectores ideológicos detentaban ya un considerable poder sociopolítico que también les había permitido incrementar esa presión a la Academia. El caso más notorio se había producido en 2006, cuando los legisladores que estaban redactando el nuevo Estatuto de la Comunidad Autónoma Andaluza pidieron consejo a la Academia sobre la conveniencia de emplear desdoblamientos léxicos del tipo 'diputados y diputadas'. La respuesta oficial de la RAE fue que dichos desdoblamientos eran innecesarios, ya que el género masculino puede ser utilizado con significado genérico para lograr una mayor economía a la hora de expresarnos, si bien es cierto que en ningún momento los calificó como errores, ya que desde el punto de vista gramatical no tienen nada de erróneos. La insatisfacción con dicha respuesta provocó altisonantes declaraciones por parte de determinadas figuras sociopolíticas que ostentaban un importante altavoz mediático, tales como la Directora del Instituto Andaluz de la Mujer, Soledad Ruiz, quien cargó duramente contra la RAE porque, según ella, dicha institución intentaba "invisibilizar a las mujeres, en un lenguaje tan

5 Por poner solo algunos ejemplos de textos periodísticos sobre la cuestión del sexismo lingüístico en los años inmediatamente anteriores a la publicación del "Informe Bosque" podemos citar A. Gaitero (2005): "Entrevista Eulàlia Lledó Cunill: «La lengua no es sexista, es un espacio de libertad y te deja decir lo que quieras»", Diario de León.es, 08/10/2005.; J. Corbella (2007): «El lenguaje entre géneros». Panamá: De Prensa.com.; Tereixa Constenla, (2008): “El lenguaje es sexista ¿Hay que forzar el cambio?", El País, 14/06/2008; C. Núñez, (2008): «Los roles de hombres y mujeres se cambian hablando, pero sobre todo haciendo». Vizcaya: El Correo Digital; José María Ridao, (2008): “Nebrija y la intervención sobre la lengua”, El País, 14/06/2008; Ricardo Martínez de Rituerto (2009): “Ni miembros ni 'miembras"”, El País, 18/03/2009; Francisco Rodríguez Adrados (2010): “La lengua española no es sexista”, La Razón, $4 / 06 / 2010$. 
rico como el español, que tiene masculino y femenino" (Díaz Salgado, 2011, 114-115), o Antonio García, fundador de la Asociación de Hombres por la Igualdad de Género (Ahige), quien, en una entrevista para El País en 2008', se quejaba de que "la RAE debería haberse puesto a la cabeza y no ir detrás del proceso de cambio que vivimos. Las palabras tienen que estar al servicio de las personas y no al revés".

Sobra decir que la respuesta directa y pública ${ }^{7}$ de la RAE ante la consulta efectuada por los legisladores que estaban redactando el nuevo Estatuto de la Comunidad Autónoma Andaluza desmiente también la tercera afirmación de la profesora Demonte, cuando dice que "(...) la Academia, si tenía una opinión, podría haber hecho sugerencias oportunamente ante informes específicos y no lo ha hecho".

En definitiva, aunque, tal como señalaba Violeta Demonte, no había una gran demanda social, desde ciertos sectores ideológicos llevaban años presionando para que el tema al menos sí que estuviese en la palestra. De hecho, esto había provocado la publicación en 2008 del libro de José Antonio Martínez El lenguaje de género y el género lingüístico, ensayo que supuso un primer intento de contra argumentación de las posturas más radicales de algunos de los impulsores del lenguaje inclusivo. Ante este panorama, tal como explicaba la académica Soledad Puértolas a $B B C$ Mundo, la Academia llevaba más de un año dándole vueltas a cómo intervenir en este asunto sin "pecar de intromisión" (Vilella, 2012), y la respuesta fue el "Informe Bosque"

Y es que, si la publicación del "Informe Bosque" en 2012 cayó como un jarro de agua fría entre los sectores ideológicos impulsores de ese lenguaje inclusivo, fue probablemente debido a que,

6 Se toma la cita de Tereixa Constenla, “El lenguaje es sexista ¿Hay que forzar el cambio?", El País, 14 de junio de 2008

7 Dicha respuesta fue publicada con el título de "Informe Emitido por la RAE Relativo al Uso Genérico del Masculino Gramatical y al Desdoblamiento Genérico de Los Sustantivos" en la Revista Española de la Función Consultiva. Para la referencia completa ver bibliografía. 
tras esa enorme presión ejercida por estos durante la década anterior, esperaban con ilusión que las academias de la lengua española en algún momento acabaran por mostrarles públicamente su apoyo, y se declararan a favor de este tipo de lenguaje. Por poner solo un ejemplo, tan solo siete años antes de la publicación del texto de la Academia, la lexicógrafa catalana Esther Forgas Berdet había concluido ilusionada que:

(...) es posible esperar que, instituciones que están al servicio de la sociedad como lo está la Academia, lleguen algún día al acuerdo de regular este nuevo concepto de cortesía que incluye tanto las cuestiones de género como las de raza o religión (...) y se propongan modificar o reconducir sus orientaciones, para llegar a recomendar, como lo hizo tres siglos atrás el académico Cardona en la planta del Diccionario de Autoridades, el uso de un lenguaje destinado a "no herir los oídos de los más circunspectos", solo que, traducido a la sociedad del siglo XXI, esto quiere decir un lenguaje que, sin alterar ni violentar sus estructuras, no ofenda ni al individuo ni a su colectivo y que, en consecuencia, resulte más adecuado a la sensibilidad lingüística de la nueva sociedad. $(2005,14)$

Por eso la sensación de desencanto debió ser aún mayor cuando, en lugar de esto, los defensores del lenguaje inclusivo se encontraron con el "Informe Bosque", que no es desde luego una declaración de apoyo público a ese tipo de lenguaje, pero tampoco es ni mucho menos lo que muchos interpretaron que era, ni decía muchas de las cosas que según algunos decía, ni cometía tampoco algunos errores que muchos le atribuyeron, como vamos a ir viendo a continuación.

\section{Interprestaciones erróneas entre los partidarios del lenguaje inclusivo}

Explicaba Violeta Demonte en la misma entrevista a la que hacíamos referencia al comienzo del artículo que: 
El problema de estos debates es que se realizan a través de los medios de comunicación, duran poco tiempo y, sí, ha habido reflexiones interesantes, pero no creo que todas las reflexiones y todo el debate se hayan podido reflejar, entre otras cosas, porque no ha sido pausado, porque documentos como el de la Academia que salen de pronto, sorpresivamente, suscitan reacciones, reciben atención durante unos días y el debate se lleva a los extremos, sin dar oportunidad a la reflexión lenta que haría falta. (Soca, 2012)

En efecto. En los días siguientes a su publicación no fueron pocos precisamente quienes se lanzaron a comentar, responder o directamente atacar a través de los medios de comunicación al "Informe Bosque" tras únicamente una primera lectura apasionada $^{8}$ del texto, en lugar de haber esperado a hacer una segunda lectura más pausada, reflexiva y objetiva del mismo. Y esto provocó que rápidamente se impusieran en general una serie de interpretaciones erróneas del informe, que se han consolidado y perpetuado desde entonces.

La primera de ellas, la más extendida y quizá la más injusta, es la que sostiene desde entonces que el "Informe Bosque" realizaba una condena radical y absoluta a todas las guías de lenguaje no sexista y a todas sus propuestas. En este sentido, desde el primer momento personas como June Fernández, directora de la revista con enfoque de género Píkara Magazine, consideraban que el manifiesto “(...) niega la mayor y deslegitima la defensa del lenguaje inclusivo", llegando las interpretaciones más radicales, como la de la filóloga Mercedes Bengoechea, a denunciar el texto como "parte de una campaña de destruir los avances de la mujer ${ }^{9 \prime}$. Como decimos, esta lectura del texto se extendió y

8 Sobre cómo la discusión en torno a los temas lingüísticos en general y en torno al Informe Bosque en particular se articuló en torno al afecto pasional véase Llamas Saíz, 2013, 200.

9 Ambas citas se toman de Paula Vilella (2012) “¿Es sexista el idioma español?”, BBC Mundo, 8 marzo 2012. 
se consolidó tanto que otra especialista en sexismo lingüístico como la profesora Eulalia Lledó todavía declaraba en 2018, es decir, seis años después de su publicación, que "el de 2012, conocido como informe Bosque, era un documento destinado a criticar y desprestigiar las guías, era bastante específico" (Zas Marco, 2018). Tan asentada está esta interpretación, especialmente entre los partidarios del lenguaje no sexista, que incluso un artículo publicado cuatro años después del "Informe Bosque", y que sí que había sido fruto de la reflexión pausada que reclamaba Violeta Demonte, como es el de la profesora Antonia María Medina Guerra titulado "Las alternativas al masculino genérico y su uso en el español de España", a pesar de desarrollar una argumentación correcta, partía de esta premisa errónea. Así, ya desde el segundo párrafo del artículo se afirmaba que:

El texto, escrito por Ignacio Bosque y suscrito por otros 26 académicos de la Real Academia Española, nace como respuesta a las recomendaciones de las muchas guías de lenguaje no sexista publicadas en España en los últimos años. Como representación, por tanto, de un amplio elenco, se elige, al parecer al azar, nueve guías (Bosque, 2012; 17), cuya crítica -suponemos- debe servir de amonestación a todas las publicadas y de advertencia disuasoria a las que pudieran publicarse, pues el hecho de que semejantes textos vean la luz genera un conflicto de intereses. $(2016,185-186)$

Como decimos, la premisa de partida de todo el artículo es incorrecta, porque el "Informe Bosque" no nace como respuesta a las recomendaciones de las muchas guías de lenguaje no sexista publicadas en España en los años anteriores a su publicación, esto es, como respuesta a todas las guías, sino que lo hace como respuesta solo a algunas de ellas: en concreto, a las que presentan las propuestas y actitudes más radicales. De hecho, la afirmación del profesor Bosque de que "las que identifico con siglas o abreviaturas en la relación que aparece al final constituyen tan solo una muestra de ese extenso catálogo" $(2012,1)$ hace referencia 
simplemente a que nueve guías son solo una mínima parte del total de las publicadas en los años anteriores, pero en ningún caso quiere expresar que se hayan cogido nueve al azar, ni quiere decir, en absoluto, que lo que se analice o reproche de estas nueve guías se tenga que considerar que se le está reprochando exactamente igual a todo el corpus de guías y manuales de lenguaje no sexista. Por lo tanto, la interpretación tan extendida de que la elección de las nueve guías que analiza el profesor Bosque se presenta como hecha al azar para representar al corpus completo de guías publicadas hasta entonces y la suposición de que, en consecuencia, lo que se les reproche a esas nueve guías debe servir de amonestación a todas las publicadas y por publicar son tan gratuitas como erróneas.

Evidentemente, esta primera premisa de partida nacida de sendas suposiciones erróneas lleva a la profesora Medina Guerra a seguir realizando interpretaciones igualmente equivocadas, ya que nacen de esas primeras suposiciones, como cuando señala que algunas de las afirmaciones del "Informe Bosque" responden a "(...) un deseo de argumentar y respaldar una idea negativa preconcebida sobre las guías (...)”. Según ella:

Quizá por eso se evita mencionar la coordinada por el catedrático de Lengua Española de la Universidad de Valencia, Antonio Briz Gómez, y publicada por el Instituto Cervantes con el apoyo del Instituto de la Mujer, Guía de comunicación no sexista (2011), de la que podemos suponer el académico no tiene mejor opinión que de las demás, ya que ni siquiera se alude a ella para que sirva de ejemplo. En este trabajo sí se citará en distintas ocasiones, no solo por el importante valor referencial que tiene en cuanto publicación de una institución creada para la promoción y enseñanza de la lengua española (...). (Medina Guerra, 2016, 187)

Como vemos, la primera premisa de partida errónea, es decir, que lo que opine Ignacio Bosque de las guías de las que habla en su informe es lo mismo que opina de todas las guías que cons- 
tituyen el corpus completo de las publicadas en años anteriores, la lleva a una segunda suposición errónea: el profesor Bosque no tiene mejor opinión de la Guía de comunicación no sexista (2011) coordinada por Antonio Briz Gómez, y publicada por el Instituto Cervantes con el apoyo del Instituto de la Mujer, que de las demás que critica en su informe, "(...) ya que ni siquiera se alude a ella para que sirva de ejemplo". En realidad, es justo al revés: si en el "Informe Bosque" no se escoge la guía del Instituto Cervantes para que sirva de ejemplo es, precisamente, porque lo que se está denunciando en dicho informe son los excesos cometidos por algunas guías de lenguaje no sexista, la mayor parte de las cuales, en sus propias palabras “(...) han sido escritas sin la participación de los lingüistas" (Bosque, 2012, 1). Y, en cambio, la del Instituto Cervantes, precisamente porque está realizada por “(...) una institución creada para la promoción y enseñanza de la lengua española (...)" (Medina Guerra, 2016, 187), es decir, con la participación de los lingüistas, tal como reclamaba Ignacio Bosque, no incurre en esos excesos. Consecuentemente, la interpretación más lógica es que Ignacio Bosque sí que tiene una opinión mucho mejor de la guía del Instituto Cervantes que de la de CCOO o la de UGT, y por eso la deja fuera de su informe. $\mathrm{Y}$ es que el informe no pretende en ningún caso llevar a cabo "(...) una revisión crítica sobre las guías de lenguaje no sexista publicadas hasta esa fecha en España", tal como afirmaba Llamas Saiz (2013, 187). Por el contrario, como muy bien explicaba Violeta Demonte en la entrevista a la que ya hemos aludido anteriormente respondiendo a la pregunta del periodista de si “¿Diría usted que el informe trata con ecuanimidad las guías que comenta?":

No lo sé, pero no todas las guías están en el informe. Una guía muy utilizada es la del Instituto Cervantes, muy aceptada. Me dicen algunas compañeras del Instituto de la Mujer de la Universidad Autónoma de Madrid que la que más ellas utilizan es la del Cervantes. Quizá sea más equilibrada, más formal lingüísticamente hablando, pero las líneas de actuación que sugieren las guías son si- 
milares. En lo que pueden diferir algunas es en la exageración en la medida en que se deban aplicar esas normas y en qué textos... (...)

Me parece que han seleccionado algunas guías, que probablemente sean las más débiles y las ponen en cuestión. (Soca, 2012)

Es decir, Ignacio Bosque solo pretendía poner en cuestión a las guías que Violeta Demonte denomina las más débiles, que son precisamente las que más exageraban sobre la medida en que se debían aplicar las normas y en qué ámbitos, las que eran menos equilibradas y menos formales lingüísticamente hablando. En definitiva, las que más excesos y abusos cometían. No en vano, ya el mismo día siguiente a la aparición del informe, en declaraciones a El País, el profesor Bosque insistía "en que el artículo no es más que una llamada a la sensatez" (Manrique Sabogal, 2012).

Una última prueba de que el "Informe Bosque" no pretendía atacar a todos las manuales de lenguaje no sexista por el mero hecho de serlo, como hemos visto que tantas veces se ha afirmado, es la presencia entre las guías objeto de análisis del Manual de Lenguaje Administrativo no sexista del Ayuntamiento de Málaga, elaborado precisamente por Antonia María Medina Guerra en colaboración con Susana Guerrero Salazar y Marta Concepción Ayala Castro, y, sobre todo, el papel que dicho manual cumple en el informe. No en vano, ya en el segundo párrafo del mismo se marcan distancias entre este manual, al que se refiere con la abreviatura MAL, y las demás guías analizadas:

La mayor parte de estas guías han sido escritas sin la participación de los lingüistas. Constituye una importante excepción MAL, que contiene abundante bibliografía. Esta es la guía más completa de las nueve, y también la menos radical en sus propuestas. Cabe pensar que los responsables o los impulsores de las demás guías entienden que no corresponde a los lingüistas determinar si los usos verbales de los hispanohablantes son o no sexistas. (Bosque, 2012, 1) 
Como vemos, no todas las guías objeto de análisis son criticadas en el informe. Este manual en concreto es utilizado en todo momento por el profesor Bosque como contrapunto entre lo que podrían ser unas propuestas lingüísticas mesuradas, equilibradas, fruto de una reflexión adecuada y, por lo tanto, con sentido, frente a la radicalidad impositiva del resto de las guías analizadas ${ }^{10}$. Lo vemos prácticamente cada vez que se alude a MAL:

De las nueve guías que menciono, MAL es la única que acepta el uso no marcado (más comúnmente llamado genérico) del masculino, como en El trabajador debe exigir sus derechos (MAL-29) o en El alumno deberá asistir puntualmente a clase (MAL-32), donde admite que "el masculino es extensivo a las mujeres". Esta guía se limita a censurar "el uso abusivo del masculino genérico" (MAL-47), mientras que las demás no aceptan su empleo y recomiendan evitarlo en todos los casos. (Bosque, 2012, 2)

Si menciono estos ejemplos, relativos a la existencia de discrepancias entre las mujeres acerca de lo que es o no es socialmente discriminatorio, es porque en las guías que examino no se muestran discrepancias en relación con lo que es o no es verbalmente sexista (de nuevo, con la posible excepción de MAL). (Bosque, 2012, 4-5)

Los lectores curiosos e interesados que lean con atención las guías de lenguaje no sexista se formularán un gran número de preguntas lingüísticas, pero me temo que buscarán inútilmente las respuestas entre sus páginas (de nuevo, con la posible excepción de MAL). (Bosque, 2012, 8)

Solo una de las nueve guías que cito recomienda evitar la arroba como signo lingüístico en todos los contextos. Aun así, no propone sustituir L@s niñ@s vendrán a clase con ropa cómoda (MAL-88)

10 Curiosamente, sus propias autoras no lo percibieron así, ya que, varios días después de la publicación del "Informe Bosque", dedicaron un artículo de prensa a defender la gramaticalidad de su manual. Véase Antonia María Medina Guerra (2012): “Un manual no sexista gramaticalmente correcto”, Sur, 23/03/2012. 
por el equivalente con los niños, sino con las niñas y niños o con los/ as niños/as. (Bosque, 2012, 13)

La Universidad de Murcia (MUR-4) proporciona una lista de "términos que hacen referencia tanto a hombres como a mujeres". (...) MAL es la única guía que actúa con cierta cautela: "Estos listados son orientativos y no deben interpretarse como soluciones válidas en todos los contextos" (MAL-52). (Bosque, 2012, 14)

Como vemos, esta guía es en todo momento diferenciada de las demás que se tratan en el informe por ser más respetuosa con la norma del español y menos radical en sus planteamientos, precisamente por haber sido elaborada por tres reconocidas lingüistas. En definitiva, este manual y las buenas palabras que tiene siempre sobre él le sirven a Ignacio Bosque, precisamente, para ilustrar a la perfección una de las tesis que se defienden en su escrito: que una buena guía de lenguaje no sexista, para no incurrir en errores, incorrecciones o disparates, debería ser escrita, al menos, con la participación de los lingüistas, y que estos deberían ser tenidos en cuenta a la hora de "determinar si los usos verbales de los hispanohablantes son o no sexistas" (Bosque, 2012 , 1). Por eso Ignacio Bosque no critica la guía de Antonio Briz Gómez para el Instituto Cervantes, tal como vimos que señalaban tanto Antonia María Medina Guerra como Violeta Demonte, pero tampoco critica las realizadas por diversas especialistas en sexismo lingüístico como Mercedes Bengoechea, Eulalia Lledó o María Ángeles Calero Fernández ${ }^{11}$, precisamente porque, al ser obra de reconocidas lingüistas, son todas ellas guías perfectamente válidas. En cambio, las que analiza en su escrito (con la excepción ya explicada de la del Ayuntamiento de Málaga) son

11 Autoras, entre otros, de Sexismo lingüístico: análisis y propuestas ante la discriminación sexual en el lenguaje, (María Ángeles Calero Fernández, 1999); “Recomendaciones para la redacción de un discurso académico libre de sexismo y de androcentrismo". (Eulalia Lledó, 1999); Guía de estilo 2: Sexismo y redacción periodística, (Mercedes Bengoechea y María Luisa Calero Vaquera, 2003; Sugerencias para evitar el sexismo en el lenguaje administrativo, (Mercedes Bengoechea, 2005); Nombra.en.red, (Mercedes Bengoechea y José Simón, 2006); Hablemos de leyes, (Eulalia Lledó, 2008). 
obra de las secretarías, oficinas y unidades para la igualdad de distintas instituciones que, por muy bienintencionadas que sean, no tienen los conocimientos lingüísticos adecuados para realizar una buena guía de lenguaje no sexista y, en la mayoría de los casos, se limitan a copiar (sin entenderlas correctamente) otras guías previas realizadas, esas sí, por lingüistas especializadas ${ }^{12}$, pero pervirtiendo tanto el tono como las propuestas originales de aquellas.

En definitiva, una lectura atenta, desapasionada y objetiva (que es lo que casi nadie hizo en su momento) permite ver claramente que el texto de Ignacio Bosque no es tanto un ataque como una defensa. Lo que pretendía el "Informe Bosque" era defender a los emisores en lengua española contra el cariz radicalmente impositivo que habían tomado muchas de esas guías, que se habían atribuido una función normativa que no les correspondía (Cabello Pino, 2019), y que acusaban de incurrir en sexismo lingüístico a todo emisor que no siguiese al pie de la letra sus directrices. Así afirma que:

(...) se deduce una y otra vez en estas guías una conclusión injustificada que muchos hispanohablantes (lingüistas y no lingüistas españoles y extranjeros, mujeres y hombres) consideramos insostenible. Consiste en suponer que el léxico, la morfología y la sintaxis de nuestra lengua han de hacer explícita sistemáticamente la relación entre género y sexo, de forma que serán automáticamente sexistas las manifestaciones verbales que no sigan tal directriz, ya que no garantizarían "la visibilidad de la mujer". (Bosque, 2012, 4)

12 Es el caso, por ejemplo, de la Guía sindical del lenguaje no sexista de UGT (2008), que no especifica en ningún momento el nombre de sus responsables, limitándose a explicar en una nota al pie de la página 7 que su fuente es la Guía para un uso igualitario del lenguaje administrativo de la Diputación de Cádiz (2005) elaborada por Marta Concepción Ayala Castro, Susana Guerrero Salazar y Antonia María Medina Guerra. 
De hecho, el "Informe Bosque" no dice absolutamente nada en contra del resto de propuestas que suelen aparecer en los manuales de lenguaje no sexista, tales como los duales aparentes y los vocablos ocupados, las fórmulas de tratamiento, los saltos semánticos, los nombres de las profesiones y cargos... etc. pues en torno a todas ellas existía ya en 2012 un gran consenso social $\mathrm{y}$, por eso mismo, un considerable reconocimiento académico. La única de las recomendaciones de los manuales de lenguaje inclusivo sobre la que gira toda la argumentación del "Informe Bosque" es la que tiene que ver con la elección de la variante lingüística para determinar el género gramatical. Pero es que es precisamente esa la que más polémica venía generando desde hacía años porque, siendo aquella sobre la que menos consenso social sigue habiendo incluso a día de hoy, era sobre la que más taxativas se mostraban la mayoría de las guías publicadas durante aquel periodo. Por ejemplo, ya ocho años antes de la publicación del "Informe Bosque", en el texto "Lenguaje sexista" (2002) de la Federación de Mujeres Progresistas se decía explícitamente:

Los errores más frecuentes en el empleo del Lenguaje, son:

- Utilización de masculino plural, o del masculino singular, para englobar al conjunto de mujeres y hombres (las invisibiliza) [...]

Es precisamente esto lo que tienen en común las guías seleccionadas por Ignacio Bosque para su informe (con la ya explicada excepción de $M A L)$, en las que "(...) el rechazo a toda expresión del masculino destinada a abarcar los dos sexos es marcadísimo $(\ldots)$ " $(2012,5)$ y en las que "se entiende, de manera poco justificada (...) que hay siempre discriminación en las expresiones nominales construidas en masculino con la intención de abarcar los dos sexos" $(2012,8)$. Es decir, en estas guías seleccionadas, al igual que en otras de las publicadas durante la década anterior, se dictaminaba taxativamente y sin matizaciones de ningún tipo que el uso del masculino genérico resulta sexista y discriminato- 
rio para la mujer siempre. Así lo ilustra el informe, entre muchos otros, con el ejemplo de la guía de CCOO, donde se afirma que "el uso del masculino con valor genérico implica un trato lingüístico discriminatorio" (Bosque, 2012, 6).

Es ante este presupuesto ante el que se rebela el académico, para llevar a cabo una defensa y una reivindicación de un recurso lingüístico usado a diario por millones de hispanohablantes con total normalidad. Entendía Ignacio Bosque que no podía pasar a proscribirse un recurso de la lengua que "está firmemente asentado en el sistema gramatical del español" $(2012,6)$ y a acusar implícita o explícitamente a aquellos que lo usaran de sexistas, tal como hacían esas guías, solo porque los autores de las mismas así lo dictaminaran. Así lo aclaraba en unas declaraciones para El País apenas cinco días después de la publicación de su informe:

Bosque insiste en que el artículo no es más que una llamada a la sensatez. Asegura que en el texto se critica la suposición gratuita de que una serie de pautas del lenguaje común, usadas por todos los hispanohablantes, son sexistas. Pero añade: “No hay ninguna razón para suponer que lo sean, ni para tachar de sexista a la mayor parte de la población hispanohablante por el simple hecho de usarlas". (Manrique Sabogal, 2012)

En definitiva, Ignacio Bosque se estaba erigiendo en portavoz de todo ese sector de la población que sentía que lo que hacían muchas de las guías de lenguaje no sexista era algo más que simplemente ofrecerle posibilidades lingüísticas a escoger libremente, y que, por el contrario, percibían que se les pretendía imponer una forma de expresarse artificiosa y antinatural con la fuerza de ese "despotismo ético o moral" del que ya hablara José Antonio Martínez en 2008 cuando explicaba que:

En todo caso -con la excepción de ciertas decisiones ortográficas, y algunas concesiones iniciales a los autores o «autoridades»-, 
la Academia ha seguido mayormente en su labor normativa el criterio del uso más generalizado. En términos coloquiales, se diría que la Academia está a verlas venir: observa y describe los usos de la lengua (el sentido y la forma de las palabras, las construcciones sintácticas), selecciona algunos, los potencia y apoya, y relega o condena otros -deslegitimando en todo caso los empleos aberrantes respecto del sistema de la lengua-. Selecciona, prohíbe en unos casos y prescribe en otros, pero nunca se inventa ningún hecho lingüístico.

Los promotores del lenguaje políticamente correcto también observan los usos, sobre todo el léxico, de la lengua, declaran incorrectos aquellos términos que revelan o podrían incitar sentimientos, pensamientos o actitudes cívica o moralmente incorrectos, y finalmente se proponen reemplazarlos por denominaciones de nuevo cuño, inéditas, ideadas en los gabinetes del lenguaje políticamente correcto.

He aquí una situación un tanto paradójica: la aristocrática y elitista Academia fundamenta toda su labor en la que podría llamarse «iniciativa popular»; mientras que las organizaciones de origen democrático parecen confiar más en la «iniciativa privada», en la práctica de un «despotismo ético o moral». $(2008,53)$

Lo que sentía gran parte de la población con respecto a ese carácter impositivo que ciertos sectores del feminismo lingüístico imprimían a sus propuestas lo expresaba muy bien el periodista Ricardo de Querol (2012) en otro artículo en El País, también pocos días después de la publicación del famoso informe, cuando decía:

(...) en esta polémica los que estamos en un aprieto somos, sobre todo, quienes compartimos la sensibilidad combativa con la discriminación de la mujer pero nos sentimos muy incómodos dentro del apretado corsé lingüístico de lo políticamente correcto.

A los medios nos llegan esos manuales de lenguaje no sexista que elaboran grupos de expertos en igualdad de algunas universi- 
dades e instituciones. Los he leído con interés (...) Pero he concluido que no puedo cumplirlos. Violaría reglas de la RAE y de nuestro Libro de Estilo, e incumpliría nuestra obligación de publicar textos claros, fáciles de leer y de entender. Los manuales antisexistas son bienintencionados pero maniqueos: dan a entender que si no estás con ellos, estás contra ellos. Si no escribo "los ciudadanos y las ciudadanas", o peor aún "1@s ciudadan@s", iestoy reforzando el machismo histórico, volviendo invisible a la mitad de la población? ¿Tengo que escribir "la juventud" en vez de "los jóvenes", "el vecindario" en vez de "los vecinos", aunque no signifique exactamente lo mismo, para no parecer excluyente?

Como vemos, no eran solo Ignacio Bosque y las academias quienes en 2012 consideraban que tildar de sexista el uso del masculino genérico por defecto en todos los contextos lingüísticos posibles, tal como se hacía en las guías y manuales más radicales, era a todas luces algo absurdo que no reflejaba en absoluto el sentir de la sociedad de la época.

Y es que, desde ciertos sectores impulsores del lenguaje inclusivo se ha querido difundir muchas veces la imagen de la RAE “(...) como una institución misógina, sexista, patriarcal y reaccionaria que busca mantener el statu quo frente al avance de una tendencia de cambio" (Olguín, 2013, 11). Mercedes Bengoechea, por ejemplo, en su artículo "Lo femenino en la lengua: sociedad, cambio y resistencia normativa. Estado de la cuestión", dedicaba el Epígrafe 3. Resistencia normativa a explicar:

(...) la postura claramente ideológica de la RAE de detener el proceso de transformación hacia la feminización del castellano e imponer su visión androcéntrica de la lengua, cuando la sociedad ha decidido cambiar la sociedad que sustentaba ciertos usos verbales y se sustentaba en ellos. $(2008,58)$

Y más recientemente Hortensia Moreno Esparza ha escrito que “(...) la Real Academia Española es una institución autorita- 
ria cobijada en una tradición añeja y sustentada en el principio de «aquí mando yo» y «aquí se hace como yo digo». «Porque lo digo yo»" (2017, 213). Pero lo cierto es que presentar a la sociedad hispanohablante en su conjunto como deseosa de cambiar un uso verbal como el masculino genérico en favor de cualquier otra alternativa de las que proponen las guías, pero no pudiendo hacerlo solo porque la Academia se lo impide, resulta una visión de la realidad completamente maniquea, que distaba mucho de la realidad en 2012, y lo sigue haciendo ahora. De hecho, la propia Mercedes Bengoechea en 2008, es decir, solo cuatro años antes del "Informe Bosque", no parecía tan contundente sobre esta cuestión cuando hablaba de que:

(...) el género gramatical masculino parece empezar a cuestionarse muy débilmente como el género capaz de representar sistemáticamente a lo masculino y lo femenino para denotar seres sexuados. Se van produciendo realizaciones que dejan entrever que la función "neutralizadora" y no marcada del género gramatical masculino empieza a encontrar dificultades y a trastornarse en un mundo discursivo cada vez más feminizado. ${ }^{13}(2008,49)$

Esta afirmación sí que se ajustaba más a la realidad lingüística de la sociedad de la época: una variante lingüística para expresar el género gramatical inclusivo, el masculino genérico, con una primacía de siglos sobre las demás, que en 2008 apenas parecía empezar a cuestionarse muy débilmente, y algunas de cuyas realizaciones dejaban entrever que podía empezar a encontrar dificultades. Es decir, un posible movimiento de cambio e innovación que apenas comenzaba a apuntar leves indicios. Pero la función de las academias no es precisamente la de promover cambios lingüísticos en la sociedad, como erróneamente piensa mucha gente, sino la de sancionar como norma del español aquellos cambios que se hayan consolidado plenamente por el uso

13 La cursiva es nuestra. 
frecuente que los propios hablantes cultos hayan hecho de una nueva variante lingüística en detrimento de otra anterior. Esto es, básicamente, lo que intentaba explicar el profesor Bosque en su informe con las siguientes palabras:

Llama la atención el que sean tantas las personas que creen que los significados de las palabras se deciden en asambleas de notables, y que se negocian y se promulgan como las leyes. Parecen pensar que el sistema lingüístico es una especie de código civil o de la circulación: cada norma tiene su fecha; cada ley se revisa, se negocia o se enmienda en determinada ocasión, sea la elección del indicativo o del subjuntivo, la posición del adjetivo, la concordancia de tiempos o la acepción cuarta de este verbo o aquel sustantivo.

Nadie niega que la lengua refleje, especialmente en su léxico, distinciones de naturaleza social, pero es muy discutible que la evolución de su estructura morfológica y sintáctica dependa de la decisión consciente de los hablantes o que se pueda controlar con normas de política lingüística.

(...) la historia de cada lengua no es la historia de las disposiciones normativas que sobre ella se hayan dictado, sino la historia de un organismo vivo, sujeto a una compleja combinación de factores, entre los que destacan los avatares de los cambios sociales y las restricciones formales fijadas por el sistema gramatical. Como es obvio, no existe institución ante la que haya que manifestarse para exigir que el sustantivo sol, el nombre del astro rey, deje de ser masculino en español, a la vez que luna es femenino, y demandar que las cosas sean exactamente al revés, como sucede en alemán. (Bosque, 2012, 15-16)

Con ellas, Bosque claramente explicaba que tampoco le correspondía a las academias censurar ni prohibir el uso del masculino genérico en virtud de su supuesto carácter sexista, por mucho que se le pidiera insistentemente desde ciertos sectores ideológicos que así lo hiciera, tal como ya hemos visto que lle- 
vaba años sucediendo ${ }^{14}$ y tal como seguiría pasando tras la publicación del informe ${ }^{15}$. Esta, en esencia, es la idea central que vertebra todo su escrito.

Sin embargo, en lugar de como la defensa de la validez del masculino genérico que en realidad era, el informe fue erróneamente tomado por los defensores del lenguaje inclusivo como una condena a todas las propuestas del lenguaje no sexista y, en especial, un ataque sin contemplaciones a las formas desdobladas. Esto dio pie a tres líneas de contra argumentación entre los defensores del lenguaje inclusivo que se han utilizado repetidamente desde entonces para desacreditar esa supuesta condena:

$\left.1^{\circ}\right)$ La primera de ellas pretendía demostrar que las formas desdobladas no eran ajenas al sistema de la lengua española, tal como supuestamente habría afirmado Bosque, sino que, más bien al contrario, habían formado parte de él desde muy pronto. Tanto es así que ya las usaba con profusión el autor del Cantar de mío Cid, cada vez que se refería a "mugieres e uarones, burgeses e burgesas". Era este, por cierto, un argumento que en 2012 no tenía nada de novedoso, pues ya lo había expuesto Soledad de Andrés en 1999, es decir, catorce años antes que el "Informe Bosque", y desde entonces se había utilizado ya con cierta recu-

14 Véanse en la página 3 las palabras de Soledad Ruiz y Antonio García.

15 Apenas unos días después de la aparición del informe, Inmaculada de la Fuente (2012) en un artículo en El País insistía una vez más en el mismo argumento al afirmar que:

Ciertamente, la RAE tiene competencia para decidir lo que es correcto y lo incorrecto. Lo propio de la RAE es la norma, y por tanto, no se puede negar su función pedagógica respecto a los excesos de unas Guías o de un lenguaje políticamente correcto que tal vez hayan pretendido subsanar de golpe desigualdades seculares. Un papel que la RAE tendría que haber asumido en vez de limitarse a criticarlo o incluso a ironizar sobre su polémico empeño o su escaso éxito.

Lo que confirma nuestra idea de que el texto no fue leído correctamente por la mayoría de la gente que lo criticó, pues, como acabamos de ver, una de las cuestiones que intenta explicar (sin mucho éxito) el Informe Bosque es, precisamente, que esa función no le corresponde a la RAE. 
rrencia. Este primer argumento demuestra una vez más cómo la primera lectura rápida y apasionada del texto de Bosque consolidó en el imaginario colectivo de los defensores del lenguaje inclusivo ciertas ideas sobre el mismo que son incorrectas, y le atribuyó a Bosque argumentos que no son suyos. Porque en ningún lugar del texto se afirma que las formas desdobladas sean ajenas al sistema gramatical de la lengua española. Quizá la confusión venga motivada por este párrafo:

Hay acuerdo general entre los lingüistas en que el uso no marcado (o uso genérico) del masculino para designar los dos sexos está firmemente asentado en el sistema gramatical del español, como lo está en el de otras muchas lenguas románicas y no románicas, y también en que no hay razón para censurarlo. (Bosque, 2012, 6)

Como vemos, para defender la validez del masculino genérico Bosque argumenta, y con razón, que este está firmemente asentado en el sistema gramatical del español, pero en ningún caso afirma que los desdoblamientos sean ajenos a dicho sistema.

$\left.2^{2}\right)$ La segunda línea de contra argumentación surgía de la asunción de la idea de que el principal argumento que sustentaba la crítica académica del "Informe Bosque" era el de la agramaticalidad de las propuestas no sexistas. Esta segunda línea se basaba, por tanto, en tratar de demostrar que las dobles formas no tenían nada de incorrecto desde el punto de vista gramatical. En este sentido, el artículo de Antonia María Medina Guerra al que ya hemos aludido anteriormente se centraba en demostrar la corrección gramatical de prácticamente todas las alternativas al uso del masculino genérico, afirmando que:

(...) por tanto, las estrategias aquí aludidas podrán considerarse necesarias o no, en función de las distintas posturas ideológicas que puedan tomarse y de las implicaciones lingüísticas que de ellas se deriven; pero, como se ha visto, está injustificado tacharlas de ri- 
dículas o agramaticales y, por supuesto, resulta inadmisible la crítica de todas las publicaciones en las que se proponen como opciones o alternativas de uso. $(2016,195)$

El problema una vez más es que en ningún momento el "Informe Bosque" tacha de agramaticales per se ninguna de las estrategias del lenguaje no sexista, con la posible excepción del uso del símbolo @, con el que la propia Medina Guerra tampoco está de acuerdo. Lo que se dice en él es que las guías de lenguaje no sexista:

(...) contienen recomendaciones que contravienen no solo normas de la Real Academia Española y la Asociación de Academias, sino también de varias gramáticas normativas, así como de numerosas guías de estilo elaboradas en los últimos años por muy diversos medios de comunicación. En ciertos casos, las propuestas de las guías de lenguaje no sexista conculcan aspectos gramaticales o léxicos firmemente asentados en nuestro sistema lingüístico, o bien anulan distinciones y matices que deberían explicar en sus clases de Lengua los profesores de Enseñanza Media, lo que introduce en cierta manera un conflicto de competencias. (Bosque, 2012, 1-2)

Es decir, que algunas de las recomendaciones que incluyen las guías contravienen efectivamente normas de las academias de la lengua porque en ciertos casos, esto es, en algunos contextos de uso, pueden conculcar aspectos gramaticales o pueden anular distinciones y matices importantes para el significado. Pero no está diciendo que ninguno de esos recursos alternativos sea agramatical por defecto. Lo que pretende explicar es que si se tienen que aplicar de manera sistemática en todos los contextos lingüísticos posibles con tal de evitar a toda costa el uso del masculino genérico, tal como pretenden imponer algunas guías, sí que nos puede hacer incurrir en agramaticalidades y en pérdida de matices importantes para la información que se quiere trans- 
mitir, tal como él mismo se encarga de ilustrar más por extenso y con numerosos ejemplos extraídos de las guías que analiza a lo largo de su informe.

$3^{\circ}$ ) La tercera línea de contra argumentación contra el "Informe Bosque" incidía en señalar la supuesta incoherencia en que incurría este por criticar las dobles formas para luego hacer uso de ellas en varias ocasiones a lo largo del texto. Eulalia Lledó fue de las primeras en denunciar a través de un artículo ${ }^{16}$ y de una conferencia ${ }^{17}$ lo curioso que resultaba "criticar una cosa en la que luego se incurre" (Zas Marco, 2018). Una vez más, el argumento demuestra que la lectura del texto de Ignacio Bosque no fue en su momento tan pausada ni tan reflexiva como hubiera sido deseable. $Y$ es que, en ninguna parte del texto se dice que no se pueda hacer uso nunca de las formas desdobladas. Más bien al contrario, se recuerda específicamente las finalidades que tienen dichos desdobles en castellano, que son las mismas que tienen algunos otros recursos lingüísticos: hacer específica la diferencia de sexo entre los miembros de un colectivo cuando así lo considera oportuno el emisor libremente, y deshacer los posibles casos de ambigüedad a los que pudiera dar pie el uso del masculino genérico en determinados contextos lingüísticos. Así se nos dice que:

La RAE y la ASALE explican (Nueva gramática de la lengua española, Madrid, Espasa, 2009, § 2.2) que el desdoblamiento en la coordinación al que he hecho referencia puede tener sentido en ciertos contextos, como en No tiene hermanos ni hermanas y en otros ejemplos que allí se proporcionan. También se aclara que existen otros recursos lingüísticos que pueden deshacer fácilmente los casos de posible ambigüedad o de falta de precisión en la referencia a grupos de personas. (Bosque, 2012, 8)

16 Véase "A propòsit de l'informe Bosque", Martes, 13 de Marzo de 2012, La independent. Agència de notícies amb visió de gènere.

17 Titulada "A propósito del informe de la RAE. Que el bosque no te impida ver los árboles" (14 de marzo, 2012). 
Con estas finalidades son con las que utiliza el profesor Bosque los desdoblamientos en su texto y, por lo tanto, no incurre en ninguna incoherencia. Porque lo que se critica en el Informe Bosque no es el uso de las formas desdobladas con esta finalidad, que como hemos visto en los dos puntos anteriores es completamente natural al sistema de la lengua española desde siempre y no tiene nada de agramatical. Por el contrario, lo que Bosque, en representación de las academias, considera realmente intolerable es la nueva finalidad que algunas guías y manuales de estilo postulaban y pretendían imponer a toda costa a los emisores so pena de ser acusados de sexistas si no se seguían sus directrices a rajatabla: esta nueva finalidad no era otra que la de sustituir sistemáticamente al masculino genérico en todos y cada uno de los contextos lingüísticos posibles ya que, para los autores de dichas guías, dicho masculino genérico resulta siempre un uso discriminatorio y sexista. Es este nuevo uso el que resulta completamente ajeno al sistema de la lengua española y el que puede hacer al emisor incurrir en agramaticalidades y en pérdidas importantes de matices de significado, además de atentar contra la libertad del emisor para elegir según su propio criterio qué variante lingüística prefiere utilizar para expresar el género gramatical en español. De hecho, la persecución extrema al masculino genérico por parte de algunas guías de lenguaje inclusivo (no de todas, desde luego) y de algunas de las instituciones que las patrocinaban habían provocado en los años previos a la publicación del "Informe Bosque", y lo seguirían haciendo en los años siguientes, un rechazo, rayando a veces en el escarnio y la parodia ${ }^{18}$, por parte de esa

18 Véanse al respecto los numerosos artículos publicados en prensa tan solo en los últimos diez años: Ricardo Martínez de Rituerto, “Ni miembros ni ‘miembras"', El País, 18/03/2009; Ricardo De Querol, "No se ofendan ustedes y ustedas", El País, 6/03/2012; Winston Manrique Sabogal, “¿La lengua tiene género? ¿Y sexo?", El País, 5/03/ 2012; Ignacio M. Roca, "A propósito de una polémica lingüística: El género no es sexo. El sexo biológico no se materializa necesariamente en sexo semántico", El País, 8 de agosto de 2012; "Millones y "millonas". Los dobletes son una epidemia que continúa y que causará un perjuicio notable a la lengua", El País, 19/9/2013; "El "juego" del doblete", El País, 20/02/2016; E. 
gran parte de la sociedad a la que le molestaba que se la acusara de sexista simplemente por usar una de las múltiples variantes lingüísticas que hay para expresar el género en español.

\section{Interpertaciones erróneas entre los detractores del lenguaje inclusivo}

Hasta ahora hemos ido viendo que el "Informe Bosque" no fue correctamente leído en un primer momento por los defensores del lenguaje no sexista, lo cual le granjeó numerosas críticas. Pero lo cierto es que tampoco fue leído de la forma más acertada por algunos de los que podríamos denominar sus propios "partidarios", quienes, apoyándose supuestamente en la autoridad del informe del profesor Bosque, se lanzaron en la prensa de los días siguientes a realizar diatribas contra el lenguaje inclusivo con un tono y unas posturas mucho más radicales que las del propio informe. Algunos de ellos, como los académicos y escritores Arturo Pérez-Reverte o Javier Marías, llevaban ya años escribiendo en contra de los defensores del lenguaje inclusivo desde sus columnas semanales en la prensa española ${ }^{19}$, con un tono muy distinto al del profesor Bosque y desde unos presupuestos bastante más radicales. Como muy bien explica Hortensia Moreno Esparza:

(...) para algunos de ellos no basta con señalar las incoherencias de las reformas, con aportar buenas razones, razones de peso, gramaticales, tradicionales, institucionales, para detenerlas. No.

En el discurso de los más duros exponentes del conservadurismo lingüístico hay una hostilidad expresa. No basta con exponer

\footnotetext{
Álvarez, "Concepción Company: El lenguaje inclusivo es una tontería". La voz de Galicia, 5/01/2018.

19 Véanse por ejemplo Javier Marías, "Cursilerías lingüísticas", El País, 20/03/1995; "El lenguaje sexista", El País, 11/04/1995; "Narices con poco olfato", El País, 17/12/2006; "El pelma ante las plastas", El País, 13/07/2008; Arturo Pérez Reverte, "Miguel Hernández era un falócrata", El Semanal, 31/12/2006; "Aceituneros y aceituneras", El Semanal, 17/12/2006; "La osadía de la ignorancia", El Semanal, 19/03/2006.
} 
doctos razonamientos, además hay que insultar, ridiculizar, subrayar la ignorancia y la estupidez de quienes se atreven a proponer, por ejemplo, la feminización de algún término, o la abolición -joh pecado!- del masculino como genérico. Lo más llamativo es que su autoridad, su prestigio, su legitimidad en el mundo público -en el campo de las letras, en el espacio académico-se adorne con el ingenio proverbial de los grandes cultivadores de la sátira. Y nos dicen: "siglos de tradición me respaldan: aquí las mujeres no tienen nada que decir". (2017: 2011)

Nada hay de todo eso en el "Informe Bosque": ni hostilidad expresa, ni insulto, ni ridiculización, ni sátira ${ }^{20}$. Tan solo "buenas razones, razones de peso, gramaticales, tradicionales, institucionales". Sin embargo, a muchos defensores del lenguaje inclusivo las ramas de la polémica y el ruido mediático que se formó en torno a la publicación del informe no les dejó ver el bosque del contenido real del mismo y, como hemos ido viendo hasta ahora, asimilaron erróneamente el discurso del profesor Bosque al de los más duros exponentes del conservadurismo lingüístico.

Un caso distinto lo constituye la publicación pocos días después de ver la luz el "Informe Bosque" de otro texto titulado "Acerca de la discriminación de la mujer y de los lingüistas en la sociedad: manifiesto de apoyo a D. Ignacio Bosque", que en principio tenía "como objetivo mostrar que las conclusiones del informe del Prof. Bosque son inobjetables y que somos muchos los lingüistas que -independientemente de nuestro sexo y edadsuscribimos sus conclusiones" (Fábregas et al., 2012, 1). Fue este manifiesto el que dio pie a la respuesta por parte del lingüista Juan Carlos Moreno Cabrera a través de un escrito titulado

20 Tal como demostró Carmen Llamas Saíz “(...) el Informe de la RAE, desde la perspectiva de la teoría de la valoración, apreció y juzgó las GLNS, pero no expresó sentimientos de afecto" $(2013,199)$, y por lo tanto, titulares como "Las guías de la ira académica costaron entre 7000 y 19000 euros" que ella misma señala aparecido en el $A B C$ el 7 del 3 de 2012 muestran una vez más el poco rigor con el que se leyó en general el texto. 
"«Acerca de la discriminación de la mujer y de los lingüistas en la sociedad». Reflexiones críticas", en el que Moreno empezaba por denunciar que dicho manifiesto:

(...) no es lo que dice ser (es decir, un desagravio de unos insultos que se asegura que han sido dirigidos a algunas de las personas firmantes de este informe, entre las que se encuentra su redactor, el profesor Ignacio Bosque), sino una argumentación, fundamentalmente equivocada a mi modesto entender, de cómo quienes se dedican a la lingüística han de razonar sobre el sexismo lingüístico. $(2012,1)$

Y pasaba a continuación a desmontar esa argumentación equivocada del manifiesto de apoyo, demostrando entre otras cosas que el principal error de aquel texto estaba en que había tomado las recomendaciones de las guías de lenguaje no sexista como si fueran dirigidas a la lengua natural, es decir, al habla diaria y espontánea, cuando en realidad dichas recomendaciones estaban pensadas para la lengua cultivada:

Las lenguas cultivadas se crean con unos determinados fines y a partir de una serie de manipulaciones de carácter cultural e ideológico. Precisamente, las guías de uso lingüístico no sexista suelen ir destinadas al lenguaje administrativo (una de ellas lleva en el título la expresión Manual de lenguaje administrativo no sexista), judicial o político, que son variedades en las que se puede y se debe intervenir de modo consciente de acuerdo con parámetros ideológicos. Estas intervenciones no se pueden juzgar, como se hace en el manifiesto que considero $a q u i^{21}$, desde el punto de vista de la lengua natural y de la competencia gramatical natural, sino desde el punto de vista de la intervención sobre la lengua. (...) (Moreno Cabrera, 2012, 6)

Y decimos que el manifiesto de apoyo al profesor Bosque en lugar de ayudar a una correcta lectura del "Informe Bosque" lo

21 La cursiva es nuestra. 
que hizo más bien fue perjudicarla, porque este reproche de Moreno Cabrera fue a partir de entonces tomado por muchos erróneamente como si fuese una crítica hacia el "Informe Bosque", cuando en realidad Moreno Cabrera se la estaba dirigiendo a los autores de dicho manifiesto, que habían hecho su propia argumentación, que no era necesariamente igual a la de Bosque. Esto consolidó a partir de entonces una línea de contra argumentación que se aprovechaba del reconocido prestigio de Moreno Cabrera en el campo de la lingüística para utilizar su crítica como si hubiese sido dirigida directamente al "Informe Bosque", cuando no es así. De este modo todavía en 2018 Eulalia Lledó seguía sosteniendo en una entrevista que el "Informe Bosque" "(...) confundía gramática con uso. Era un escrito que tomaba las guías como si fueran la palabra de dios, y casi nunca hablan de norma o gramática, sino de uso. En este sentido, Bosque erró el tiro y confundió las dos cosas" (Zas Marcos, 2018). Sin embargo, ese reproche, si se le podía dirigir a alguien era a los autores del manifiesto de apoyo, pero no al propio profesor Bosque, quien en su informe no confundía en absoluto gramática con uso, ni lengua natural con lengua cultivada. Más bien al contrario, lo que hacía Ignacio Bosque era, por un lado, criticar que algunas guías (ya fuese consciente o inconscientemente) fueran algo ambiguas y no dejaran claro su ámbito de actuación, tal como se ve en estas palabras:

Un buen paso hacia la solución del "problema de la visibilidad" sería reconocer, simple y llanamente que, si se aplicaran las directrices propuestas en estas guías en sus términos más estrictos, no se podría hablar. Mucho me temo, sin embargo, que las propuestas no estén hechas para ser adaptadas al lenguaje común. Unas veces se dice expresamente en las guías, pero otras queda tan solo sobrentendido: se supone que los cambios que se solicitan han de afectar únicamente al lenguaje oficial..$^{22}(2012,11)$ 
Y, por otro lado, Bosque dejaba muy claro que no estaba de acuerdo con que se abogara porque el lenguaje oficial (la lengua cultivada) fuese cada vez más artificial y se separase cada vez más del lenguaje común (la lengua natural):

Se aplicarían, pues, a los textos legales o administrativos (lengua escrita) y a los discursos públicos, las declaraciones, las ruedas de prensa y otras manifestaciones de la lengua oral. Dicho de una manera más clara: se ve como algo enteramente natural que la autoridad, el responsable o el gestor que desdobla usuarios y usuarias o ciudadanos y ciudadanas se olvide de su desdoblamiento cuando ya no esté delante de un micrófono o de una cámara. Una vez abandone la tribuna o el estudio de grabación, dirá que "va a cenar con unos amigos", sin intención de excluir a las mujeres, o que "tiene que ir al colegio a recoger a sus hijos", sin que hayamos de suponer que no tiene hijas. Hablará, en una palabra, como todo el mundo.

No me parecen insignificantes las implicaciones que conlleva la aceptación de este sorprendente cambio de registro. Precisamente ahora que se trabaja para que el lenguaje de los textos jurídicos se acerque en alguna medida al español común, las propuestas para "visibilizar a la mujer" en el idioma parecen encaminarse en el sentido opuesto. Se trata, al parecer, de lograr que el lenguaje oficial se diferencie aún más del real ${ }^{23}$. A los tan denostados eufemismos de los políticos y los economistas, que enmascaran o edulcoran, como sabemos, tantos aspectos de la realidad, parece que ha de agregar-

23 Curiosamente, una de las especialistas en lenguaje sexista que más críticas se mostraron con el Informe Bosque, Mercedes Bengoechea, tan solo un año antes parecía darle sin saberlo la razón a Bosque al afirmar que:

El lenguaje jurídico del siglo XXI debe ser un lenguaje accesible a la ciudadanía, con redacción clara, coherente y sencilla, que atienda "a criterios de funcionalidad comunicativa". Debe además, por imperativo legal, utilizar lenguaje no sexista. Es necesario que ambos requisitos sean compatibles y no se caiga en la pesadez e incoherencia que han demostrado los primeros textos que, con muy buena voluntad, pero con técnica deficiente, han tratado de incorporar lenguaje no sexista a su redacción. Aunque la falta de práctica lo dificulte, el lenguaje jurídico no sexista debe cumplir con los requisitos de eficacia, eficiencia, concisión, claridad, sencillez y coherencia que se exigen al lenguaje jurídico del siglo XXI $(2011,22)$ 
se ahora un nuevo código artificial, ajeno al lenguaje común, constituido por nuevos circunloquios, restringidos - como antes - al mundo oficial. A la vez, se acepta paradójicamente su propia artificiosidad al reconocer implícitamente que no tienen aplicación en la lengua de todos los días. $(2012,12)$

Como vemos, Ignacio Bosque en su informe tomaba una postura con respecto a una tendencia en auge con la que él, en representación de las academias (y de una gran parte de la sociedad), no estaba de acuerdo. Pero en ningún caso significa eso que no fuera consciente de la existencia de la lengua natural y la lengua cultivada, y mucho menos que las confundiera. Simplemente abogaba porque no aumentara aún más la distancia entre ellas.

\section{Conclusiones}

En definitiva, desde su publicación en 2012 el "Informe Bosque" ha cargado injustamente con la fama de ser el azote del lenguaje inclusivo cuando, como hemos venido mostrando, no es así en absoluto. De hecho es un texto mucho más moderado en sus planteamientos y en su tono que otras obras académicas anteriores como, por ejemplo, el Diccionario Panhispánico de Dudas $(2005)^{24}$. A pesar de que frecuentemente se haya pretendido calificar el texto como una especie de instrumento de represión de las academias contra aquellos que quieran usar libremente los recursos lingüísticos propios del lenguaje no sexista, como se ha visto, su intención es justamente la contraria. El "Informe Bosque" no pretende prohibir nada, sino simplemente defender a los emisores en castellano que libremente quisieran seguir haciendo uso del masculino genérico de la presión a la que estaban siendo sometidos por algunos organismos e instituciones patrocinadores de guías de lenguaje no sexista que, confundiendo y

24 Véase la crítica a esta obra que realiza Mercedes Bengoechea en el apartado "Rechazo abierto a las dobles formas" en su artículo "Lo femenino en la lengua: sociedad, cambio y resistencia normativa. Estado de la cuestión" (2008). 
tergiversando (consciente o inconscientemente) las propuestas realizadas a lo largo de los años por reconocidas lingüistas, habían adoptado un carácter radicalmente impositivo sobre los emisores que, claramente, no les correspondía.

\section{Bibliografía}

Bengoechea Bartolomé, M. (2008) “Lo femenino en la lengua: sociedad, cambio y resistencia normativa. Estado de la cuestión", Lenguaje y textos, 27, 37-68.

Bengoechea Bartolomé, M. (2011) “El lenguaje jurídico no sexista, principio fundamental del lenguaje jurídico modernizado del siglo XXI", Anuario Facultad de Derecho-Universidad de Alcalá, 4, 15-26.

Bosque, I. (2012) "Sexismo lingüístico y visibilidad de la mujer". 1 de marzo de 2012. <http://www.rae.es/sites/default/files/ Sexismo_linguistico_y_visibilidad_de_la_mujer_0.pdf> [consulta: 3 de octubre de 2017]

Cabello Pino, M. (2019) "Academias de la lengua frente a guías de lenguaje no sexista: un problema de delimitación de competencias", Tonos digital. Revista electrónica de estudios filológicos, 37, Julio. <http://www.tonosdigital.es/ojs/index.php/tonos/ article/view/2244/1070> [consulta: 19 de agosto de 2019]

Constenla, T. (2012) "Son un poco antiguos en la RAE", El País, 30/07/2012. <https://elpais.com/sociedad/2012/07/30/actualidad/1343676381_917439.html> [consulta: 23 de mayo de 2018]

Constenla, T. (2008) "El lenguaje es sexista ¿Hay que forzar el cambio?", El País, 14/06/ 2008. <https://elpais.com/diario/2008/06/14/sociedad/1213394401_850215.html> [consulta: 23 de mayo de 2018]

De Andrés Castellanos, S. (1999) "Sexismo y lenguaje. El estado de la cuestión: reflejos en la prensa", en Garrido Medina, J. C. (coord.), La lengua y los medios de comunicación: actas del Congreso Internacional celebrado en la Universidad Complutense de Madrid en 1996. Volumen I, Madrid, Servicio de publicaciones de la Universidad Complutense, 258-266 
De la Fuente, I. (2012) “Y, ¿qué aportaría María Moliner al debate sobre el sexismo?", El País, 12/03/2012. <https://www.fundeu.es/noticia/y-que-aportaria-maria-moliner-al-debate-sobre-el-sexismo-6936/> [consulta: 13 de agosto de 2019]

De Querol, R. (2012) "No se ofendan ustedes y ustedas", El País, 6/03/2012. <https://elpais.com/elpais/2012/03/06/mujeres/1331013600_133101.html> [consulta: 23 de mayo de 2018]

Díaz Salgado, L. C. (2011) "Historia crítica y rosa de la Real Academia Española", en Senz, S. y Alberte, M. (eds.) El dardo en la Academia. Esencia y vigencia de las academias de la lengua española. Volumen I, Barcelona, Melusina, 21-156.

FÁbregas, A (et al.) (2012) "Acerca de la discriminación de la mujer y de los lingüistas en la sociedad: manifiesto de apoyo a D. Ignacio Boque", Tromsø, 6 de marzo de 2012. <https://manifiestolinguistica.weebly.com/> [consulta: 17 de enero de 2019]

Federación de Mujeres Progresistas (2002) Lenguaje sexista. $<$ http://americalatinagenera.org/newsite/images/doc_210_Lenguaje-sexista.pdf $>$ [consulta: 8 de agosto de 2019]

Guerrero Salazar, S. (2007) “Esbozo de una bibliografía crítica sobre recomendaciones y guías para un uso igualitario del lenguaje administrativo (1986-2006)", en Medina Guerra, A. M. (Coord.) Avanzando hacia la igualdad, Málaga, Diputación de Málaga /Asociación de Estudios Históricos sobre la Mujer, pp. 109122.

Llamas Saíz, C. (2013) “La actitud ante la lengua en el discurso de la prensa española: léxico y argumentación a propósito del sexismo lingüístico" en Llamas Saíz, C., Martínez Pasamar, C., Casado-Velarde, M., Léxico y argumentación en el discurso público actual, Frankfurt, Peter Lang.

Llamas Saíz, C. (2015) "Academia y hablantes frente al sexismo lingüístico: ideologías lingüísticas en la prensa española", Circula: revie d'ideologies linguístiques, 1, 196-215.

Lledó, Eulalia (2012) "A propòsit de l'informe Bosque", 13/03/2012, La independent. Agència de notícies amb visió de gène- 
re. $<$ http://www.laindependent.cat/index.php?option=com_content\&view=article\&id=2221:a-proposit-de-linforme-bosque\&catid=260:temes-culturals\&Itemid=306\&lang=es $>$ [consulta: 6 de agosto de 2019]

Lledó, Eulalia (2012) "A propósito del informe de la RAE. Que el bosque no te impida ver los árboles" (vídeo), Universidad Pública de Navarra, 14/03/2012. https://upnatv.unavarra.es/pub/ eulalia-lledo [consulta: 6 de agosto de 2019]

Manrique Sabogal, W. (2012) “¿La lengua tiene género? ¿Y sexo?", El País, 4/03/2012. <https://elpais.com/cultura/2012/03/04/ actualidad/1330896843_065369.html> [consulta: 23 de mayo de 2018]

Martínez, J. A. (2008) El lenguaje de género y el género lingüístico, Oviedo, Universidad de Oviedo.

Medina Guerra, A. M. (coord.) Ayala Castro, M. C.; Guerrero Salazar, S. (2002) Manual de Lenguaje Administrativo no sexista, Málaga, Asociación de Estudios Históricos Sobre la Mujer en colaboración con el Área de la Mujer (Ayuntamiento de Málaga).

Medina Guerra, A. M. (2012) “Un manual no sexista gramaticalmente correcto", Sur, 23/03/2012. <http://www.lenguayprensa.uma.es/archivo/?p=24391> [consulta: 13 de agosto de 2019]

Medina Guerra, A. M. (2016) "Las alternativas al masculino genérico y su uso en el español de España", Estudios de Lingüística Aplicada, 34, 64, diciembre, 183-205.

Moreno Cabrera, J. C. (2012) "«Acerca de la discriminación de la mujer y de los lingüistas en la sociedad». Reflexiones críticas". <http://www.pensamientocritico.org/ juamor0915.pdf $>$ [consulta: 1 de diciembre de 2019]

Moreno Esparza, H. (2017) “Lenguaje sexista / lenguaje no sexista", en Luz María Moreno Tetlacuilo y Ana María Carrillo Farga (coords.) La perspectiva de género en la salud, México, Facultad de Medicina de la UNAM, 197-218.

Morrillo Herrero, L. (2014) “Repercusión mediática del informe de Ignacio Bosque «Sexismo lingüístico y visibilidad de 
la mujer» (2012)", en Carriscondo Esquivel, F. M. (ed.), La lengua en el candelero: repercusión mediática de asuntos lingüísticos, Vigo, Academia del Hispanismo, 97-134.

Olguín, M. J. (2013) “El sexismo lingüístico, visibilidad de las mujeres y polémicas en torno a los usos del habla", VII Jornadas de Jóvenes Investigadores, Instituto de Investigaciones Gino Germani, Facultad de Ciencias Sociales, Universidad de Buenos Aires, Buenos Aires.

Real Academia Española (2006) "Informe Emitido por la RAE Relativo al Uso Genérico del Masculino Gramatical y al Desdoblamiento Genérico de Los Sustantivos", Revista Española de la Función Consultiva, 6, 307-308.

Soca, R. (2012) "Entrevista a la lingüista venezolana Violeta Demonte «Las academias no hacen falta para la unidad de la lengua»", elcastellano.org, 26/03/2012. <http://www.rebelion.org/ noticia.php?id=146959> [consulta: 15 de abril de 2019]

VILELla, P. (2012) “¿Es sexista el idioma español?”, BBC Mundo, 8/03/2012. <https://www.bbc.com/mundo/noticias/2012/03 /120308_sexismo_idioma_espanol> [consulta: 23 de mayo de 2019]

Zas Marcos, M. (2018) “Entrevista a Eulalia Lledó: «La RAE tiene la idea curiosa de que manda sobre la lengua y eso es demoledor»", eldiario.es., 19/07/2018. <https://www.eldiario.es/cultura/Eulalia-Lledo-RAE-lengua-demoledor_0_794420886.html $>$ [consulta: 6 de mayo de 2019] 
